\title{
Mapping the Lonely Landscape - Assessing Loneliness and Its Consequences
}

\author{
Niina Junttila ${ }^{1,2, *}$, Sakari Kainulainen ${ }^{3}$ and Juho Saari ${ }^{4}$ \\ ${ }^{1}$ Turku Institute for Advanced Studies, University of Turku, Finland \\ ${ }^{2}$ Department of Teacher Education, University of Turku, Finland \\ ${ }^{3}$ Diaconia University of Applied Sciences, Finland \\ ${ }^{4}$ Kuopio Welfare Research Centre, University of Eastern Finland, Finland
}

\begin{abstract}
The subjective nature of loneliness poses challenges for valid and reliable assessment methods - what should we ask when we want to evaluate one's loneliness? Therefore, this study aimed to compare loneliness assessed by different indicators: frequency of loneliness over the last year, number of good friends, satisfaction with existing social relationships, and the short version of the UCLA Loneliness Scale. These indicators were used to study the gender and age-related differences between lonely and non-lonely adults and as predictors for the self-reported consequences of loneliness. The sample consisted of 17,258 Finnish adults aged 30 to 60 years. Based on our results, the number of good friends had less power as an indicator for the self-reported negative consequences of loneliness than did the other indicators (i.e., satisfaction with existing personal relationships and resultant [based on confirmatory factor analysis] social and emotional loneliness factors of the UCLA Loneliness Scale). The importance of identifying loneliness in the prevention of psychosocial and economic issues, substance abuse and eating disorders, and negative consequences on health is discussed. More broadly, based on our results, we find that there is a legitimate reason to consider loneliness as a form of social inequality.
\end{abstract}

Keywords: Indicators, loneliness, measurement validity, negative consequences, UCLA loneliness scale.

Loneliness is subjective anxiety that causes feelings of being without the type of relationships one desires; that is, loneliness is a discrepancy between one's real and desired relationships [1]. It can be experienced as a personal failure in the valued area of interpersonal relationships [2] and as a part of a spoiled identity, and it may therefore cause serious damage to a person's overall self-efficacy and ability to cope with the different dimensions of everyday life. Since loneliness relies on one's subjective perception of unsatisfied social relationships, it may be-and often is-relatively independent from the actual number of social contacts one has or the amount of solitude one experiences; in other words, being alone does not necessarily imply feeling lonely nor does being lonely necessary require aloneness [3-5]. This subjective and complex nature of loneliness possesses challenges for its evaluation. Since we cannot identify lonely people just by the amount of time they spent with others, we need proper questions to distinguish between the positive or neutral state of aloneness and the subjective anxious arising form of loneliness.

\footnotetext{
*Address correspondence to this author at the Department of Teacher Education, University of Turku, FIN-20014 University of Turku, Finland. E-mail: niina.junttila@utu.fi
}

Comparing objective aloneness (social vulnerabilities) and subjective loneliness, the latter has more negative consequences on a person's mental and physical health [6]. Furthermore, material vulnerabilities and loneliness tend to be mutually re-enforcing; for instance, people who receive food aid are mostly living under the poverty line and loneliness is about ten times more common in this group than within average population. If objective material vulnerabilities are connected with subjective scarcities, their combined impact is even stronger [7].

In popular and political debates that are emerging in many, if not most, postindustrial societies, loneliness is quite commonly interpreted as a one-dimensional global phenomenon. However, it is commonly known in the scientific community that loneliness can be further divided into two separate loneliness dimensions: social and emotional loneliness. These dimensions were first described by Robert Weiss [8] in his fundamental research on the nature of human loneliness. Currently, the commonly accepted definition of social loneliness is that it refers to the absence of a social network or to the feeling that one is not part of a group. Emotional loneliness, in turn, refers to the lack of a close, intimate attachment to another person $[4,8$, 9]. While studies on gender differences in social loneliness 
have shown either higher levels for women or no statistically significant differences between genders, emotional loneliness has been reported to be more frequent in men, especially during childhood and adolescence [10-12].

\section{Assessing Loneliness}

Over the course of loneliness research, the indicators and evaluation methods used to capture the subjective nature of loneliness have varied between simple questions (e.g., "Are you lonely?") and strictly validated scales, including sets of questions concerning one's subjective feelings and behavioral patterns known to diverge between lonely and non-lonely individuals [13]. While using single questions, respondents have usually been asked to either give dichotomous answers (yes/no) or to estimate the frequency of their loneliness feelings (e.g., never, rarely, sometimes, often, always). These indicators have been easy for the respondents to answer and easy for researchers to code and report. The drawbacks to this method have been that respondents may not understand the meaning of the phenomenon in the same way as the researchers (e.g., the difference between being alone and feeling lonely) and that due to social desirability bias, individuals tend to underestimate their own negative behavior and overestimate their own positive social behavior [14]. Among studies adapting these self-labeling questions (e.g., "I'm a lonely person"), women tend to report more loneliness than men, which contradicts the results of other studies on the differences between genders $[12,15,16]$. That is, the prevalence and valence of loneliness seems to depend on the questions used to evaluate it.

As Heinrich and Gullone [16] and Hughes and colleagues [13] underlined, it is important to note that while loneliness is often caused by a quantitative lack of social networks, it is more greatly influenced by the qualitative elements of these social networks, such as satisfaction with existing personal relationships, perceived social acceptance, and feelings of connectedness and closeness. Indeed, a study by Jones [17] revealed that a person's number of friends is not a good predictor of loneliness because while the actual number of social contacts may not vary between lonely and non-lonely people, the types of contacts do. This means that while nonlonely people engage in interactions with good friends and relatives, lonely people may engage more with strangers and acquaintances (i.e., people whose company does not fulfill their need for intimate and close relationships). Thirty years later, Jin [18] studied modern types of social networks, such as the internet-based Facebook, and came into same conclusion; lonely people had less overlap between their Facebook and real life (face-to-face) friends. That means, that the amount of "friends" and the quality of friendships does not necessary match.

Therefore, many researchers argue that either sets of questions posed by researchers or subjective evaluations of respondents' satisfaction with their personal social relationships are more valid questions while studying the phenomenon of loneliness [19-21]. Among loneliness scales meant to assess adults' loneliness, the most commonly used and validated scale within different contexts and cultures is the UCLA Loneliness Scale developed by Russell, Peplau, and Cutrona [9]. This scale evaluates subjective feelings of loneliness and/or social isolation and has a basis in Weiss's [8] social and emotional loneliness theory. Based on Russell, Cutrona, McRae, and Gomez's [22] results, the correlation between number of friends and satisfaction with social relationships was .22, whereas the correlation between loneliness evaluated by UCLA and satisfaction was stronger (-.44). This result is in line with the quantitative versus qualitative discussion of loneliness presented above that loneliness seems to be more related to the subjective feelings and satisfaction than to the actual number of social relationships. This should be notified while elaborating the prevalence and valence, as well as age and gender differences in loneliness assessed by different sets of questions.

\section{Consequences of Loneliness}

Satisfying social relationships that minimize the anxious and negative feeling of loneliness are essential for good mental and physical health. Like Rokach [23] states, "Loneliness, which is a complex and multifaceted experience, is always very painful, severely distressing and individualistic" (p. 3). Accordingly, previous research has produced a wide range of unfavorable outcomes and negative consequences of loneliness. Beginning with aspects concerning psychosocial well-being and mental health, research has reported consequences such as social isolation, substance abuse, eating disorders, delinquency, depression, social anxiety/phobia and fears, avoidant personality and borderline personality disorders, schizophrenia, self-injury, suicide attempts, and suicides [3, 12, 16, 24].

Recently, Cacioppo and his colleagues published results on the serious effects of loneliness not only on psychological well-being and mental health but also on person's physical health. Among these are issues such as diminished sleep quality, obesity, cardiovascular health risks, systolic blood pressure, Alzheimer's disease, cognitive decline, dementia, increase of morbidity, and mortality [3, 25, 26]. The effects of loneliness on a person's physical health, either directly or indirectly via unfavorable behavioral patterns such as substance abuse or self-injury, seem undeniable. Hawkley and Cacioppo [3] concluded that chronic loneliness increases morbidity and mortality through its impact on genetic, neural, and hormonal mechanism of human beings.

According to Halleröd and Larsson [27], social exclusion is a mix of problems and "deprivation poverty often coincides with long-standing health problems, anxiety and sleeping problems and, also, loneliness"(pp. 20). It is not easy to evaluate which one comes first-poverty or loneliness - but it is obvious that they are linked. On the one hand, some causal mechanisms between loneliness and deprivation are quite self-evident. Lonely persons tend to have fewer social contacts that are crucial for generating social capital and, in turn, vital for reaching valuable goods and services. Lower social capital is also linked to lower numbers of social interactions. On the other hand, poor persons tend to have lower social status (understood as a positional good), which attracts less social interest and fewer interactions and therefore makes the poor more vulnerable to loneliness. 
In general, based on the wide array of negative and serious consequences of loneliness, it should be identified (and thus intervention can be provided) more effectively. In order to do so, we need valid and reliable indicators to identify this phenomenon.

\section{AIMS OF THE PRESENT STUDY}

Since the results of a person's loneliness seems to depend on the kind of question asked our first main aim was to compare results from different indicators used to assess adults' self-reported feelings of loneliness. For this purpose, we used questions regarding 1) whether the respondent had experienced frequent or constant feelings of loneliness during past year, 2) the number of his/her good friends, 3) his/her satisfaction with existing social relationships, and the short version of UCLA Loneliness Scale hypothesized to consist factors of social and emotional loneliness. For comparison, we studied the gender and age related differences on the prevalence and valence of loneliness assessed by different indicators.

Second, we aimed to analyze the predictive value of these four indicators of loneliness to predict the self-reported negative consequences of loneliness. Among self-reported negative consequences of loneliness, we explored three sets of variables: 1) consequences related to health and psychosocial issues (illnesses, depression, lack of initiative, fear of future, isolating home, social fears, divorce), 2) consequences related to socio-economic issues (unemployment, poverty, incurring of a debt, gambling, comfort shopping), and 3) consequences related to problems with drinking and eating habits (substance abuse, comfort eating, loss of appetite).

\section{METHOD}

\section{Participants}

Altogether, 27,946 Finnish people voluntarily answered an internet based inquiry (in March 2014) concerning their feelings of loneliness. An invite to join the study was posted on a five-page article on the social consequences of loneliness published in the biggest newspaper in Finland, Helsingin Sanomat (circulation on Sundays, 352,541, with over 780,000 readers; the population in Finland is 5.3 million). In order to get a coherent sample in terms of the possibilities to acquire social relationships, education, family and work career, we chose men and women aged 30 to 60 years with complete answering patterns. Obvious outliers were excluded from the data. After this, the sample for this study consisted of 17,258 Finnish people divided into 6,389 men and 10,869 women; the 30 to 39 years age group included 3,048 men and 5,538 women; the 40 to 49 years age group included 2,025 men and 3,262 women; and the 50 to 60 years age group included 1,316 men and 2,069 women. As expected, a greater number of young people responded to the internet survey than did older people. In the sample, the share of students was over $(21 \%$ vs. $7 \%)$ and the share of retired persons was under (5\% vs. $25 \%$ ) the shares of the population of Finland. In the resultant sample of women and men aged 30 to 60 years, the amounts of respondents represented the shares of Finnish population well.

\section{Measures}

For the purposes of this study, we used different theorybased indicators to evaluate adults' subjective feelings of loneliness. The question used as a basis for the comparison of other sets of indicators was a dichotomously coded (no/yes) question regarding whether the respondent had experienced either frequent or constant feelings of loneliness during past year. The other two single questions used as loneliness indicators were the number of good friends i.e. "How many good friends do you have?" (a number between 0 and 25) and subjective satisfaction with his/her own existent personal relationships, i.e. "How satisfied are you with your personal relationships?". For the second question, the respondents were asked to select a number between 0 (completely dissatisfied) and 10 (completely satisfied).

To measure social and emotional loneliness, we developed a Finnish version of the UCLA Loneliness Scale, version 3 [28]. In Russell's version of UCLA, the number of items has been reduced to ten, and the wording of the items and the response format has been simplified. The instruction was "Indicate how often each of the statements below is descriptive of you" and the responses were $0=$ never; $1=$ rarely; 2 = sometimes; and $3=$ often. The Cronbach's alpha reliability estimate for the whole scale was .819 in our data.

In order to explore the consequences of loneliness, we asked the respondents to choose every appropriate variable on a list prepared based on previous studies on the consequences of loneliness. The question was "Has loneliness caused you any of the following issues during your life?" and the consequences listed were illnesses, depression, lack of initiative, fear of future, isolating home, social fears, divorce, unemployment, poverty, incurring of a debt, gambling, comfort shopping, substance abuse, comfort eating, and loss of appetite.

\section{Statistical Analyses}

In order to analyze the associations and the gender and age related differences among loneliness indicators, we first needed to test the hypothesized two-factor structure of the translated version of UCLA Loneliness Scale. To test the construct validity consisting factors of social and emotional loneliness, we used confirmatory factor analysis (CFA). CFA was performed on the covariance matrices using maximum likelihood estimation with Mplus7.3 [29]. The fit of the models was evaluated using the root mean square error of approximation (RMSEA), the comparative fit index (CFI), the Tucker-Lewis Index (TLI), and the standardized root mean square residual (SRMR). The RMSEA is a measure of discrepancy per degree of freedom [30]. According to $\mathrm{Hu}$ and Bentler [31], a cutoff value close to .06 for the RMSEA indicates a good fit. The CFI indicates how much better the model fits than the independence model. The index varies between 0 and 1 , and for the model to be suitable, the value should be close to .90 [32]. However, according to Little, Card, Preacher, and McConnell [33], values between .85 and .90 are considered average. In addition, the TLI, developed by Tucker and Lewis [34], indicates how much better the model fits than the independence model. The index varies between 0 and 1 , and the value should, according to $\mathrm{Hu}$ and Bentler [31], be close to .95 for the model to be suitable. The 
SRMR is the average of the standardized residuals between the observed and the predicted covariance matrix; a cutoff value close to .08 indicates a good fit [31].

To test the regression paths between loneliness indicators and self-reported negative consequences of loneliness, we used structural equation models (with Mplus) consisting of both measured and latent variables. The rest of the analyses were conducted with basic group comparison methods. Since the sample size was large, which affects the p-values, we also calculated the Cohen's d effects size values in order to estimate the magnitude of the statistically significant differences.

\section{Results}

Descriptive statistics of the study variables for both genders are presented in Table $\mathbf{1}$

Except for the dichotomous variables of the self-reported consequences of loneliness, most of the skewness and kurtosis values were within reasonable limits; that is, the statistics were below 2.0 for skewness and 7.0 for kurtosis [35]. Table $\mathbf{1}$ also presents the statistical significance estimates ( $p$-values and Cohen's d effect size) for the differences between men's and women's self-reported loneliness and its consequences. Most of the differences between genders were statistically significant, though small in magnitude. Women reported having more friends and being more satisfied with their existing personal relationships than men. Among the UCLA Loneliness Scale items, most of the statistically significant differences indicated that men had more frequent feelings of loneliness than did women. Among self-reported consequences of loneliness, only comfort eating and unnecessary shopping were more frequently chosen by women than by men.

In order to compare the results from the different indicators of loneliness, we first tested the expected twofactor structure of the UCLA Loneliness Scale using CFA. The items were divided into factors of social and emotional loneliness based on the theoretical model of loneliness. That is, items $1,3,5,6$, and 8 were categorized into social loneliness and items 2, 4, 7, 9, and 10 into emotional loneliness. Factors were allowed to correlate; errors were assumed to be uncorrelated. The fit indexes for this first model were poor and therefore some modifications were done based on the modification indexes, factor loadings, and item r-squares.

First, the item "I feel shut out and excluded by others" was removed since its r-square was considerably smaller (.010) than those of the other items. Second, based on modification indexes, the item "I feel completely alone" was allowed to have cross-loading to the emotional loneliness factor. The nature of the item seems to estimate intense feelings of loneliness related to both social and dyadic relationships. Moreover, the errors between the items "I find myself waiting for people to call or write" (ucla5) and "I feel starved for company" (ucla8) loading into social loneliness and "I am unable to reach out and communicate with those around me" (ucla7) and "It is difficult for me to make

Table 1. Descriptive Statistics and Gender Differences for the Study Variables.

\begin{tabular}{|c|c|c|c|c|c|c|c|c|c|}
\hline & \multirow[b]{2}{*}{ max. $^{1}$} & \multirow[b]{2}{*}{ skewness } & \multirow[b]{2}{*}{ kurtosis } & \multicolumn{2}{|c|}{ Men $(n=6389)$} & \multicolumn{2}{|c|}{ Women $(n=10869)$} & \multicolumn{2}{|c|}{$\begin{array}{l}\text { Differences between } \\
\text { genders }\end{array}$} \\
\hline & & & & mean & s.d. & mean & s.d. & $\mathrm{p}$-value & Cohen's d $d^{2}$ \\
\hline Amount of good friends & 25 & 2.34 & 8.14 & 3.69 & 3.52 & 4.63 & 3.61 & .000 & -.264 \\
\hline Satisfaction with personal relationships & 10 & -.33 & -.86 & 5.12 & 2.69 & 6.14 & 2.52 & .000 & -.391 \\
\hline \multicolumn{10}{|l|}{ Items of UCLA } \\
\hline 1. I am unhappy doing so many things alone & 3 & -.13 & -.90 & 1.62 & .99 & 1.61 & .93 & .248 & - \\
\hline 2. I have nobody to talk to & 3 & -.06 & -1.16 & 1.66 & 1.05 & 1.49 & 1.02 & .000 & .164 \\
\hline 3. I cannot tolerate being so alone & 3 & .52 & -.53 & 1.04 & .93 & 1.03 & .88 & .524 & - \\
\hline 4. I feel as if nobody really understands me & 3 & -.07 & -.93 & 1.63 & .97 & 1.57 & .94 & .000 & .063 \\
\hline 5. I find myself waiting for people to call or write & 3 & -.13 & -.89 & 1.50 & .97 & 1.73 & .91 & .000 & -.245 \\
\hline 6. I feel completely alone & 3 & .64 & -.73 & 1.03 & 1.02 & .89 & .94 & .000 & .143 \\
\hline $\begin{array}{l}\text { 7. I am unable to reach out and communicate with } \\
\text { those around me }\end{array}$ & 3 & .11 & -1.01 & 1.58 & 1.02 & 1.33 & .95 & .000 & .254 \\
\hline 8. I feel starved for company & 3 & -.32 & -.23 & 1.82 & .80 & 1.96 & .73 & .000 & -.183 \\
\hline 9. It is difficult for me to make friends & 3 & -.32 & -1.03 & 1.92 & 1.01 & 1.75 & .99 & .000 & .170 \\
\hline 10. I feel shut out and excluded by others & 3 & .34 & -.84 & 1.13 & .95 & 1.21 & .95 & .000 & -.084 \\
\hline \multicolumn{10}{|l|}{ Self-reported consequences of loneliness } \\
\hline Illnesses & 1 & 2.98 & 6.91 & .09 & .28 & .08 & .28 & .728 & - \\
\hline Depression & 1 & .54 & -1.71 & .42 & .49 & .34 & .47 & .000 & .167 \\
\hline Lack of initiative & 1 & .41 & -1.83 & .46 & .50 & .37 & .48 & .000 & .184 \\
\hline Fear of future & 1 & .87 & -1.25 & .31 & .46 & .29 & .46 & .024 & .043 \\
\hline Isolating home & 1 & .05 & -1.99 & .52 & .50 & .47 & .50 & .000 & .100 \\
\hline Social fears & 1 & .80 & -1.37 & .35 & .48 & .29 & .46 & .000 & .128 \\
\hline Divorce & 1 & 4.06 & 14.49 & .06 & .24 & .05 & .21 & .000 & .044 \\
\hline Unemployment & 1 & 4.23 & 15.92 & .07 & .26 & .03 & .18 & .000 & .179 \\
\hline Poverty & 1 & 2.83 & 5.99 & .12 & .32 & .08 & .27 & .000 & .135 \\
\hline Incurring of a debt & 1 & 3.39 & 9.51 & .09 & .29 & .06 & .23 & .000 & .115 \\
\hline Gambling & 1 & 4.60 & 19.15 & .08 & .26 & .02 & .15 & .000 & .283 \\
\hline Comfort shopping & 1 & .89 & -1.21 & .19 & .39 & .36 & .48 & .000 & -.389 \\
\hline Substance abuse & 1 & 1.31 & -.29 & .34 & .47 & .16 & .37 & .000 & .426 \\
\hline Comfort eating & 1 & .23 & -1.95 & .32 & .47 & .51 & .50 & .000 & -.392 \\
\hline Loss of appetite & 1 & 2.95 & 6.73 & .08 & .28 & .09 & .28 & .298 & - \\
\hline
\end{tabular}

Note ${ }^{1}$ Minimum score for every variable is 0 .

Note ${ }^{2}$ Cohen's d effect sizes: $d>.199=$ small; $d>.499=$ medium; $d>.799=$ large . 
friends" (ucla9) loading into emotional loneliness were allowed to correlate. The first pair refers to an acute need for social connections, whereas the other pair seems to indicate a specific problem with developing closer personal relationships with others.

After these modifications, an adequate fit for the twofactor model was obtained: CFI was .964, TLI was .943, RMSEA was .067, and SRMR was .036. The resultant factor solution of social and emotional loneliness and the standardized loadings of each item are presented in Fig. (1). For the purposes of subsequent analyses, the latent sum scores of social and emotional loneliness were calculated based on the standardized item loadings.

To compare the subjective feelings of loneliness assessed by the different indicators, we first tested the differences between groups of respondents who answered either "no" or "yes" to the question of whether they had experienced frequent or constant feelings of loneliness during past year. As expected, the group with frequent or constant feelings of loneliness scored higher on the other indicators of loneliness: the number of good friends (-), satisfaction with personal relationships (-), and social $(+)$ and emotional $(+)$ factors of loneliness (see Table 2). For both men and women, the effect sizes of the differences in satisfaction with personal relationships, social loneliness, and emotional loneliness were large in magnitude (varying between 1.117 and -1.488), whereas for the differences in the number of good friends, the effect sizes were only small to medium in magnitude

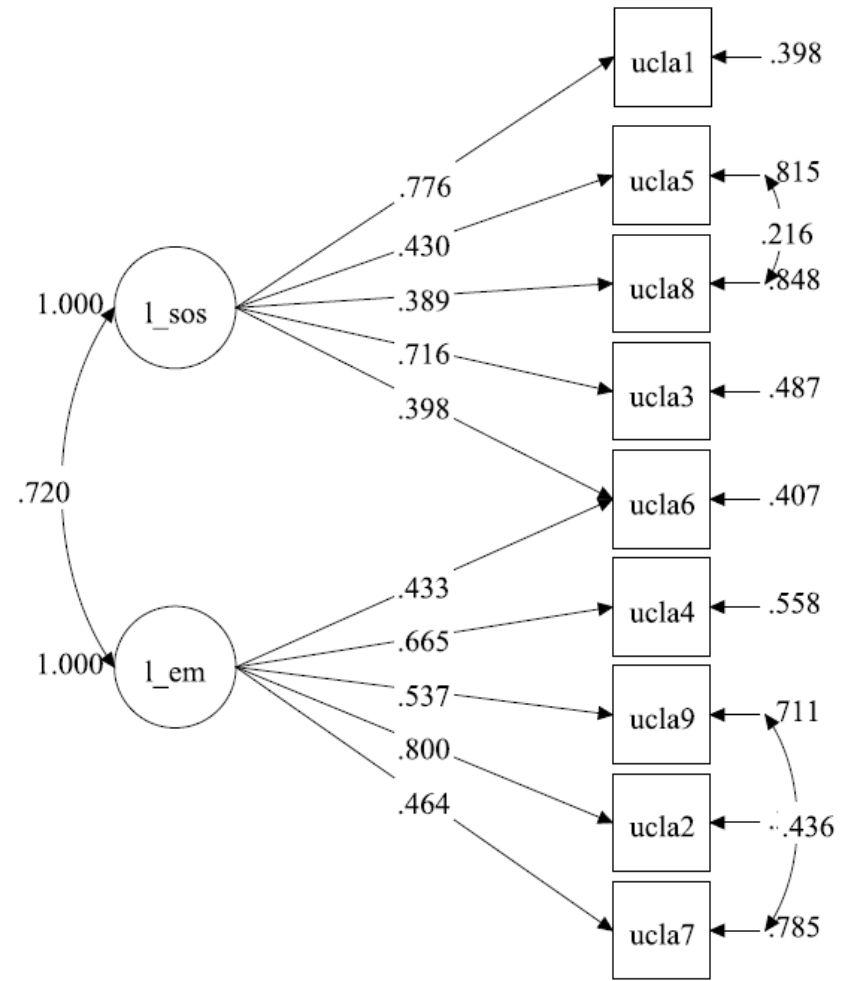

Fig. (1). Factor Structure and Standardized Item Loadings of the Loneliness Scale.

Table 2. Differences in Loneliness Indicators between Groups with Existent and Non-Existent Feelings of Loneliness and between Genders.

\begin{tabular}{|c|c|c|c|c|c|c|}
\hline \multirow[b]{3}{*}{$\operatorname{Men}(n=6389)$} & \multicolumn{2}{|c|}{$\begin{array}{l}\text { No frequent or consistent feelings of } \\
\text { loneliness during past year } \\
\text { ( } n=3099 \text { for men; } n=6076 \text { for women) }\end{array}$} & \multicolumn{2}{|c|}{$\begin{array}{l}\text { Frequent or consistent feelings of loneliness } \\
\text { during past year } \\
\text { ( } n=3290 \text { for men; } n=4793 \text { for women) }\end{array}$} & \multicolumn{2}{|c|}{ Difference between groups } \\
\hline & mean & s.d. & mean & s.d. & p-value & Cohen's d \\
\hline & & & & & & \\
\hline \multirow{2}{*}{$\begin{array}{l}\text { Amount of good friends } \\
\text { Satisfaction with personal } \\
\text { relationships }\end{array}$} & 4.47 & 3.90 & 2.95 & 2.94 & .000 & .440 \\
\hline & 6.59 & 2.25 & 3.74 & 2.31 & .000 & 1.250 \\
\hline \multirow{2}{*}{$\begin{array}{l}\text { Social loneliness } \\
\text { Emotional loneliness }\end{array}$} & 2.58 & 1.49 & 4.88 & 1.60 & .000 & -1.488 \\
\hline & 3.36 & 1.87 & 5.82 & 1.81 & .000 & -1.337 \\
\hline \multicolumn{7}{|l|}{ Women $(n=10869)$} \\
\hline \multirow{2}{*}{$\begin{array}{l}\text { Amount of good friends } \\
\text { Satisfaction with personal } \\
\text { relationships }\end{array}$} & 5.29 & 3.71 & 3.79 & 3.28 & .000 & .428 \\
\hline & 7.23 & 2.00 & 4.75 & 2.42 & .000 & 1.117 \\
\hline \multirow{4}{*}{$\begin{array}{l}\text { Social loneliness } \\
\text { Emotional loneliness }\end{array}$} & 2.94 & 1.36 & 4.99 & 1.50 & .000 & -1.432 \\
\hline & 3.20 & 1.76 & 5.43 & 1.85 & .000 & -1.235 \\
\hline & \multicolumn{2}{|c|}{ Men (all) } & \multicolumn{2}{|c|}{ Women (all) } & \multicolumn{2}{|c|}{ Difference between genders } \\
\hline & mean & s.d. & mean & s.d. & $p$-value & Cohen's d \\
\hline Amount of good friends & 3.69 & 3.52 & 4.63 & 3.61 & .000 & -.264 \\
\hline $\begin{array}{l}\text { Satisfaction with personal } \\
\text { relationships }\end{array}$ & 5.12 & 2.69 & 6.14 & 2.52 & .000 & -.391 \\
\hline Social loneliness & 3.77 & 1.93 & 3.84 & 1.75 & .000 & -.038 \\
\hline \multirow[t]{3}{*}{ Emotional loneliness } & 4.62 & 2.21 & 4.18 & 2.12 & .000 & .203 \\
\hline & \multicolumn{2}{|c|}{ Men aged $30 / 40 / 50^{1}$} & \multicolumn{2}{|c|}{ Women aged $30 / 40 / 50^{1}$} & \multicolumn{2}{|c|}{$\begin{array}{l}\text { Difference between age groups } \\
\text { (men/women) }\end{array}$} \\
\hline & mean & s.d. & mean & s.d. & $p$-value & ns. diff. ${ }^{2}$ \\
\hline Amount of good friends & $3.94 / 3.52 / 3.35$ & $3.57 / 3.44 / 3.49$ & $4.92 / 4.33 / 4.33$ & $3.64 / 3.49 / 3.63$ & $.000 / .000$ & $\begin{array}{l}\text { Men: ns. } 40 \\
\text { vs. } 50\end{array}$ \\
\hline $\begin{array}{l}\text { Satisfaction with personal } \\
\text { relationships }\end{array}$ & $5.12 / 5.05 / 5.23$ & $2.67 / 2.65 / 2.80$ & $6.25 / 6.01 / 6.03$ & $2.45 / 2.54 / 2.63$ & $.172 / .000$ & Men: ns. all \\
\hline Social loneliness & $3.89 / 3.74 / 3.53$ & $1.88 / 1.93 / 2.01$ & $3.95 / 3.74 / 3.71$ & $1.69 / 1.77 / 1.84$ & $.000 / .000$ & \\
\hline Emotional loneliness & $4.76 / 4.60 / 4.33$ & $2.20 / 2.21 / 2.21$ & $4.28 / 4.14 / 3.98$ & $2.11 / 2.12 / 2.12$ & $.000 / .000$ & \\
\hline
\end{tabular}

Note $^{1}$ Age groups are 30 = aged 30-39 years; 40 = aged 40-49 years; 50 = aged 50-60 years. Note ${ }^{2}$ Non-significant differences between post hoc group comparisons; otherwise all differences between groups were statistically significant at level $p<.05$. 
(.428 and .440).

Comparing genders, women reported having more good friends and more satisfaction with their existing personal relationships, yet they reported having statistically significantly more social loneliness than did men. Men's emotional loneliness was statistically significantly more frequent than women's. However, the effect sizes for these differences were rather small overall. Comparing age groups within genders, the ANOVA results revealed that younger men (aged 30-39) had more good friends, despite also reporting more social and emotional loneliness than men within older (40-49 and 50-60) age groups. Among women, the younger group reported having more good friends and being more satisfied with their personal relationships than women in the older groups. However, like the younger men, younger women also reported having more feelings of both social and emotional loneliness.

Next, we used these four indicators of loneliness (the number of good friends, satisfaction with personal relationships, and social and emotional loneliness) as predictors for the self-reported consequences of loneliness. The listed consequences were related to health and psychosocial issues (illnesses, depression, lack of initiative, fear of future, isolating home, social fears, divorce), economical issues (unemployment, poverty, incurring of a debt, gambling, comfort shopping), and problems with drinking and/or eating (substance abuse, comfort eating, loss of appetite). As presented in Table $\mathbf{3}$, among the indicators of loneliness, the number of friends least predicted self-reported negative consequences. The statistically significant standardized regression coefficients were low, and unlike other indicators, the direction was not consistent; that is, considering most of the variables, higher numbers of friends predicted more negative self-reported consequences. For example women who had more friends reported having more depression, social fears, fears of future, and comfort eating.

For both men and women, higher satisfaction with existing personal relationships predicted less self-reported negative consequences of loneliness. In line with this, higher feelings of social and emotional loneliness predicted more negative consequences of loneliness for both men and women. Overall, the regression coefficients with selfreported consequences were stronger for social and emotional loneliness than for the other two indicators (number of friends, and satisfaction with personal relationships).

In Table 3 we also present the percentage of lonely people who reported a particular consequence. By lonely people, we mean those who reported that they had experienced either frequent or constant feelings of loneliness during past year. The number of these respondents who reported psychosocial consequences of loneliness was high. Close to $70 \%$ of lonely men and women reported that due to their loneliness, they have isolated home. More than half of lonely men and women reported depressive feelings and lack of initiative. Around $40 \%$ had a fear of the future as well as social fears. Forty percent of men reported substance abuse and comfort eating, whereas corresponding percentages for women were 20 and 60 .

In order to get a more global view of the relationship between loneliness indicators and the self-reported consequences, we constructed latent variables estimating the

Table 3. Significant Regression Coefficients of Indicators of Loneliness Predicting Self-Reported Consequences, and the Percentage of Lonely Men and Women Reporting Each Consequences.

\begin{tabular}{|c|c|c|c|c|c|c|c|c|c|c|}
\hline & \multicolumn{4}{|c|}{ Men $(n=6389)$} & \multicolumn{4}{|c|}{ Women ( $n=10$ 869) } & \multicolumn{2}{|c|}{$\begin{array}{l}\% \text { of lonely }{ }^{1} \text { with the } \\
\text { consequence }\end{array}$} \\
\hline & $\begin{array}{l}\text { Amount of } \\
\text { good } \\
\text { friends }\end{array}$ & $\begin{array}{l}\text { Satisfaction } \\
\text { with personal } \\
\text { relationships }\end{array}$ & $\begin{array}{c}\text { Social } \\
\text { loneliness }\end{array}$ & $\begin{array}{l}\text { Emotional } \\
\text { loneliness }\end{array}$ & $\begin{array}{l}\text { Amount of } \\
\text { good friends }\end{array}$ & $\begin{array}{l}\text { Satisfaction } \\
\text { with personal } \\
\text { relationships }\end{array}$ & $\begin{array}{c}\text { Social } \\
\text { loneliness }\end{array}$ & $\begin{array}{l}\text { Emotional } \\
\text { loneliness }\end{array}$ & $\begin{array}{c}\text { Men } \\
(n=3290)\end{array}$ & $\begin{array}{c}\text { Women } \\
(n=4793)\end{array}$ \\
\hline 1. Illnesses & - & -.071 & .181 & .067 & - & -.073 & .180 & .082 & 13.7 & 15.1 \\
\hline 2. Depression & - & -.097 & .279 & .174 & .022 & -.085 & .241 & .193 & 61.0 & 52.8 \\
\hline 3. Lack of initiative & - & -.074 & .173 & .189 & - & -.049 & .163 & .179 & 60.0 & 51.0 \\
\hline 4. Fear of future & - & -.047 & .222 & .123 & .043 & -.042 & .245 & .131 & 42.9 & 43.4 \\
\hline 5. Isolating home & - & -.116 & .138 & .214 & - & -.088 & .154 & .248 & 68.3 & 66.5 \\
\hline 6. Social fears & .031 & - & - & .418 & .020 & - & - & .419 & 45.3 & 37.6 \\
\hline 7. Divorce & - & - & .110 & .030 & - & -.036 & .061 & - & 8.5 & 6.1 \\
\hline 8. Unemployment & - & -.087 & .090 & .121 & - & -.033 & .067 & .108 & 11.3 & 6.2 \\
\hline 9. Poverty & - & -.099 & .127 & .104 & - & -.089 & .133 & .044 & 18.4 & 13.3 \\
\hline $\begin{array}{l}\text { 10. Incurring of a } \\
\text { debt }\end{array}$ & - & -.073 & .157 & - & - & -.084 & .110 & .031 & 14.2 & 9.3 \\
\hline 11. Gambling & -.026 & -.036 & .092 & - & -.021 & -.044 & .053 & .033 & 10.7 & 3.5 \\
\hline $\begin{array}{l}\text { 12. Comfort } \\
\text { shopping }\end{array}$ & .026 & -.034 & .073 & .070 & .025 & -.039 & .105 & .051 & 23.5 & 44.0 \\
\hline 13. Substance abuse & .032 & -.043 & .179 & - & - & -.051 & .109 & .048 & 41.8 & 21.6 \\
\hline 14. Comfort eating & .045 & - & .154 & .068 & .033 & -.048 & .120 & .080 & 39.5 & 60.7 \\
\hline 15. Loss of appetite & - & -.034 & .166 & - & .024 & - & .151 & .049 & 12.8 & 13.2 \\
\hline $\begin{array}{l}\text { Health and } \\
\text { psychosocial issues }^{1} \\
(1-7)\end{array}$ & - & -.146 & .348 & .377 & .031 & -.109 & .345 & .405 & \multirow{2}{*}{\multicolumn{2}{|c|}{$\begin{array}{c}\mathrm{R}^{2}=.574 \text { for men; } \\
\mathrm{R}^{2}=.537 \text { for women } \\
\mathrm{R}^{2}=.141 \text { for men; } \\
\mathrm{R}^{2}=.118 \text { for women }\end{array}$}} \\
\hline $\begin{array}{l}\text { Economic issues } \\
(8-12)\end{array}$ & - & -.124 & .181 & .135 & - & -.111 & .169 & .124 & & \\
\hline $\begin{array}{l}\text { Problems with } \\
\text { drinking/eating } \\
(13-15)\end{array}$ & .090 & -.131 & .656 & .154 & - & -.120 & .539 & .237 & \multicolumn{2}{|c|}{$\begin{array}{c}\mathrm{R}^{2}=.692 \text { for men; } \\
\mathrm{R}^{2}=.594 \text { for women }\end{array}$} \\
\hline
\end{tabular}


three sets of loneliness consequences. The first latent consisted of health and psychosocial issues (illnesses, depression, lack of initiative, fear of future, isolating home, social fears, divorce), the second consisted of the economic issues (unemployment, poverty, incurring of a debt, gambling, comfort shopping), and the third consisted of the problems with drinking and eating (substance abuse, comfort eating, loss of appetite). The fit of the model was acceptable: CFI was .834, TLI was .807, RMSEA was .045, and SRMR was .041. The standardized regression coefficients and rsquares are presented in Table $\mathbf{3}$. In line with the results from the separate variables, the number of friends had only a weak predictive value on all three sets of consequences, whereas the predictive values of social and emotional loneliness were among the strongest. Overall, the four indicators of loneliness explained $57 \%$ of men's and $54 \%$ of women's health and psychosocial issues and $69 \%$ of men's and $59 \%$ of women's self-reported problems in drinking and eating. For economic issues, the corresponding values were $14 \%$ for men and $12 \%$ for women.

\section{DISCUSSION}

Based on our results, among the four sets of indicators of loneliness, the least predictive value for self-reported negative consequences of loneliness was the single question concerning the number of good friends. This indicator had the least significant regression loadings into the three sets of negative consequences of loneliness. Moreover, the existent loadings were very low in magnitude and mostly went against the expected outcome, that is, a higher number of good friend predicted more depression, social fears, fear of future, and comfort eating. This implies either that the concept of "good friend" has numerous meanings for different persons or, alternatively, an exaggerated number of "friends" may have some instrumental value in compensating for various fears (e.g., a person fearing something hoards friends in order to protect him/herself against negative emotions). Previous research has constantly supported the divergence between the objective amount of people (e.g. in big cities) and the subjective feelings of loneliness [1, 3]. Moreover, while Cacioppo et al. [6] compared the effects of objective aloneness and subjective loneliness, they find that the latter had more negative consequences on a person's mental and physical health. This is in line with our results of the low or even non-existent predictability of the question "How many good friends do you have?". Among other indicators, the findings were similar to previous research in the sense that dissatisfaction with personal relationships and social and emotional loneliness predicted more negative health and psychosocial outcomes, more financial problems, and more substance abuse and eating disorders [3, 12, 16, 24, 25].

An important finding and contribution to subsequent studies is the validation of the hypothesized two-factor structure of the short version (version 3) of the UCLA Loneliness Scale. Although the scale was originally developed based on the theory of social and emotional loneliness, it has been used as a one-dimensional global indicator of loneliness. In line with previous expectations [4], the frequency between men's and women's emotional loneliness is divergent, as are the negative consequences of social and emotional loneliness [16]. For example, while social loneliness did not predict social fears among men or women, emotional loneliness was found to be a strong predictor for social fears affecting everyday social situations. On the other hand, social loneliness predicted problems with drinking and eating habits much stronger than did emotional loneliness.

The third finding to be emphasized is the frequency of the negative consequences of loneliness: 50 to $70 \%$ of both men and women reported that their feelings of loneliness have caused them to feel isolation and depression as well as a lack of initiative. Around $40 \%$ of men and women reported that due to their loneliness, they have social fears as well as a fear of the future. Albeit loneliness has been constantly reported to have strong associations with mental health [5, 16] these self-reported prevalence rates of negative consequences were unexpected high. Along with mental health problems, also physical health problems were remarkably associated with loneliness. For example $40 \%$ of men reported substance abuse and comfort eating as a consequences of their loneliness. Among women, as many as $60 \%$ had experienced comfort eating caused by their feelings of loneliness. Cacioppo et al. $[3,25,26]$ have reported that loneliness is a severe risk factor for one's physical health and may indeed be even more fatal than smoking or obesity. The fact that these risk variables are strongly accumulative is worth careful consideration.

Overall, based on these self-reports, loneliness in Finnish adults has resulted in a great deal of negative health, psychosocial well-being, and economic related consequences. Therefore, we argue that loneliness should be systematically assessed and understood as a form of capability deficit and, consequently, of durable inequality in a society. In many ways, both its objective and subjective health and well-being consequences are likely to be comparable with those of conventional socio-economic variables, such as income, education, employment, and wealth. Clearly, there is a need to expand public policy agendas from conventional variables to also cover subjective loneliness as a main force of social issues, unhappiness, and poor health.

The obvious limitation of this study is the cross-sectional nature of the data. Even though the questions concerning the consequences were presented in a way that the respondents were asked to choose the consequences caused by their feelings of loneliness, we cannot be sure that the consequences are caused exclusively by their loneliness. Still, the strong relationship between feelings of loneliness and negative effects on health and psychosocial and economic issues is evident. In future studies, important elements to consider will be the effects of short versus longterm loneliness as well as the coping mechanisms used to minimize the negative consequences of one's loneliness. Moreover, inequality caused by loneliness should be considered in more depth, and, in particular, the role of subjective status differences in explaining the mutually reinforcing impact of material vulnerabilities and loneliness requires our systematic attention.

\section{CONFLICT OF INTEREST}

The author confirms that this article content has no conflict of interest. 


\section{ACKNOWLEDGEMENTS}

Decleared none.

\section{REFERENCES}

[1] Peplau LA, Perlman D. Perspectives on loneliness. In Peplau LA. Perlman D. Loneliness. A sourcebook of current theory, research and therapy. New York: Wiley 1982; p.120.

[2] Margalit, M. Lonely children and adolescents. Self-perceptions, social exclusion, and hope. New York: Springer 2010.

[3] Hawkley LC, Cacioppo JT. Loneliness matters: A theoretical and empirical review of consequences and mechanisms. Ann Behav Med 2010; 40: 218-27.

[4] Junttila N. Social competence and loneliness during the school years: Issues in assessment, interrelations and intergenerational transmission. Annales Universitatis Turkuensis: Turku 2010.

[5] Lindgren BM, Sundbaum J, Eriksson M, Graneheim UH. Looking at the world through a frosted window: experiences of loneliness among persons with mental ill-health. J Psychiatr Nurs Ment Health Nursing 2014; 21: 114-20.

[6] Cacioppo JT, Cacioppo S, Capitanio JP, Cole SW. The neuroendocrinology of social isolation. Annu Rev Psychol 2015; 66: 733-67.

[7] Ohisalo M, Saari J. Kuka seisoo leipäjonossa? Who is standing in the Breadline in Finland? Ruoka-apu 2010-luvun Suomessa. Sastamala: Kunnallisalan kehittämissäätiön Tutkimusjulkaisusarjan julkaisu 2014.

[8] Weiss RS. Loneliness. The experience of emotional and social isolation. Massachusetts: The MIT Press 1973.

[9] Russell D, Peplau LA, Cutrona CE. The revised UCLA Loneliness Scale: Concurrent and discriminant validity evidence. J Person Soc Psychol 1980; 39: 472-80.

[10] Junttila N, Vauras M. Loneliness of school-aged children and their parents. Scand J Psychol 2009; 50: 211-9.

[11] Junttila N, Laakkonen E, Niemi PM, Ranta K. Modeling the interrelations of adolescents' loneliness, social anxiety and social phobia. Sci Ann Psychol Soc North Greece 2010; 8: 69-99.

[12] Junttila N, Ahlqvist-Björkroth S, Aromaa M, et al. Mothers' and fathers' loneliness during pregnancy, infancy, and toddlerhood. Psychol Educ J 2013; 50: 98-104.

[13] Hughes ME, Waite LJ, Hawkley LC, Cacioppo JT. A short scale for measuring loneliness in large surveys: results from two population-based studies. Res Aging 2004; 26: 655-72.

[14] Eisenberg N, Mussen P. The roots of prosocial behaviour in children. Cambridge: Cambridge University Press 1989.

[15] Borys S, Perlman D. Gender differences in loneliness. Person Psychol Bull 1985; 11: 63-74.

[16] Heinrich LM, Gullone E. The clinical significance of loneliness: A literature review. Clin Psychol Rev 2006; 26: 695-718.
[17] Jones WH. Loneliness and social behavior. In: Peplau LA, Perlamn D. Loneliness: a sourcebook of current theory, research and therapy. New York: Wiley 1982; pp. 238-52.

[18] Jin B. How lonely people use and perceive Facebook. Comput Hum Behav 2013; 29: 2463-70.

[19] De Jong Gierveld J, Van Tilburg T. A 6-item scale for overall, social and emotional loneliness: Confirmatory tests on survey data. J Aging 2006; 28: 582-98.

[20] DiTommaso E, Spinner B. The development and initial validation of the Social and Emotional Loneliness Scale for Adults (SELSA). Person Individ Diff 1993; 14: 127-34.

[21] Hoza B, Bukowski WM, Beery S. Assessing peer network and dyadic loneliness. J Clin Child Psychol 2000; 29: 119-28.

[22] Russell DW, Cutrona CE, McRae C, Gomez M. Is loneliness the same as being alone? J Psychol 2012; 146: 7-22.

[23] Rokach A. Loneliness Updated: an introduction. In: Rokach A Loneliness updated: Recent research on loneliness and how it affects our lives. New York: Routledge 2013.

[24] Levine MP. Loneliness and eating disorders. J Psychol 2012; 146 243-57.

[25] Cacioppo JT, Hawkley LC, Crawford E, Ernst JM, Burleson MH, Kowalewski RB. Loneliness and health: Potential mechanisms. Psychosom Med 2002; 64: 407-17.

[26] Cacioppo JT, Patrick W. Loneliness. Human nature and the need for social connection. New York: W W Norton \& Company 2008.

[27] Halleröd B, Larsson D. Poverty, welfare problems and social exclusion. Int J Soc Welfare 2008; 17: 15-25.

[28] Russell D. The UCLA Loneliness Scale (version 3): Reliability, validity, and factor structure. J Person Assess 1996; 66: 20-40.

[29] Muthén LK, Muthén BO. Mplus version 7.3. Statistical analysis with latent variables. Los Angeles, CA: Muthén \& Muthén 2014.

[30] Steiger JH. Structural model evaluation and modification: an interval estimation approach. Multivar Behav Res 1990; 25: 17380.

[31] Hu L, Bentler PM. Cut-off criteria for fit indexes in covariance structure analysis: Conventional criteria versus new alternatives. Struct Equ Modeling 1999; 6: 1-55.

[32] Bentler PM. Comparative fit index in structural models. Psychol Bull 1990; 107: 238-46.

[33] Little TD, Card NA, Preacher KJ, McConnell E. Modeling longitudinal data from research on adolescence. In: Lerner RM, Steinberg L., Eds. Handbook of adolescent psychology: vol. 1. Individual bases of adolescent development. Hoboken, NJ: Wiley 2009; pp. 15-54

[34] Tucker LR, Lewis C. A reliability coefficient for maximum likelihood factor analysis. Psychometrika 1973; 38: 1-10.

[35] Curran CJ, West SG, Finch JF. The robustness of test statistics to non-normality and specification error in confirmatory factor analysis. Psychol Methods 1996; 1: 16-29.

(C) Junttila et al.; Licensee Bentham Open.

This is an open access article licensed under the terms of the Creative Commons Attribution Non-Commercial License (http://creativecommons.org/licenses/by-nc/3.0/) which permits unrestricted, non-commercial use, distribution and reproduction in any medium, provided the work is properly cited. 